Article

\title{
Dependence of Liquid Supercooling on Liquid Overheating Levels of Al Small Particles
}

\author{
Qingsong Mei ${ }^{1, *}$ and Juying $\mathrm{Li}^{2}$ \\ Received: 5 November 2015; Accepted: 17 December 2015; Published: 24 December 2015 \\ Academic Editor: Andreas Taubert \\ 1 Department of Materials Engineering, School of Power and Mechanical Engineering, Wuhan University, \\ Wuhan 430072, China \\ 2 School of Mechanical Engineering, Wuhan Polytechnic University, Wuhan 430023, China; jyli@whpu.edu.cn \\ * Correspondence: qsmei@whu.edu.cn; Tel.: +86-27-6877-2252
}

\begin{abstract}
The liquid thermal history effect on liquid supercooling behavior has been found in various metals and alloys; typically the degree of liquid supercooling $\left(\Delta T^{-}\right)$increases with the increase of liquid overheating $\left(\Delta T^{+}\right)$up to several to tens of degrees above the equilibrium melting point $\left(T_{0}\right)$. Here we report quantitative experimental measurements on the $\Delta T^{-}-\Delta T^{+}$relationship of $\mathrm{Al}$ small particles encapsulated in $\mathrm{Al}_{2} \mathrm{O}_{3}$ shells by using a differential scanning calorimeter. We find a remarkable dependence of $\Delta T^{-}$on $\Delta T^{+}$of Al small particles, extending to at least $340^{\circ} \mathrm{C}$ above $T_{0}$ of $\mathrm{Al}\left(\sim 1.36 T_{0}\right)$, which indicates the existence of temperature-dependent crystallization centers in liquid $\mathrm{Al}$ up to very high liquid overheating levels. Our results demonstrate quantitatively the significant effect of liquid thermal history on the supercooling behavior of $\mathrm{Al}$ and its alloys, and raise new considerations about the dependence of $\Delta T^{-}$on $\Delta T^{+}$at very high $\Delta T^{+}$levels.
\end{abstract}

Keywords: liquid overheating; liquid supercooling; solidification; thermal history; Al particles

\section{Introduction}

Solidification and melting are transformations basic to technological applications such as casting, crystal growth, and glass formation. Historically, the liquid thermal history was discovered to have a significant effect on the liquid supercooling behavior and thus, the nucleation and growth of crystals and their qualities [1-13]. The thermal history effect can be quantified by the relationship between liquid overheating $\left(\Delta T^{+}\right)$, which is measured by the difference between liquid temperature and the equilibrium melting point $\left(T_{0}\right)$, and liquid supercooling $\left(\Delta T^{-}\right)$, which is measured by the difference between $T_{0}$ and the temperature of solidification. Thus far, the dependence of $\Delta T^{-}$on $\Delta T^{+}$has been investigated in metals/semimetals ( $\mathrm{Bi}, \mathrm{Sn}, \mathrm{Ga})[2-5,11,14]$ and alloys [6-11]; typically $\Delta T^{-}$increases with an increase of $\Delta T^{+}$up to several to tens of degrees above $T_{0}$. Despite the fundamental and technical importance, the underlying mechanism of this phenomenon in relation to the liquid structure and the kinetics of heterogeneous nucleation of solidification is not well understood. Turnbull [14] suggested that crystals in microcavities, which are on the container or surface of impurity particles inside a melt, can be retained above $T_{0}$, i.e., they have elevated melting points. These retained crystals can serve as nuclei for solidification at a certain supercooling level, which results in an increase of $\Delta T^{-}$ with the increase of $\Delta T^{+}$[14].

The cavity theory has been quantitatively validated by various experimental results [2-5], but it was considered to be not general, e.g., the dependence of $\Delta T^{-}$on $\Delta T^{+}$in $\mathrm{Bi}, \mathrm{Sn}, \mathrm{SnSb}$ and $\mathrm{SnPb}$ was found to be either continuous or discontinuous $[10,11]$, which points to the evolution of transient short range order structures in the liquid state. Obviously, more investigations of the $\Delta T^{+}-\Delta T^{-}$ relationship (thermal history effect) in metals and alloys are needed. In the casting of $\mathrm{Al}$ alloys, liquid 
thermal history effects on the microstructure of solidification have been reported $[15,16]$. Hereby, a quantitative study of the dependence of $\Delta T^{-}$on $\Delta T^{+}$in the simple metallic system $\mathrm{Al}$ is considered to be interesting. For experimental measurements of the $\Delta T^{+}-\Delta T^{-}$relationship, a precise control of temperature and heating/cooling rate is needed, and extraneous effects (e.g., oxidation) should be excluded [3,4]. Meanwhile, in bulk continuous systems, the factors affecting the solidification process are rather accidental, and the crystallization centers in one region may have an effect on the freezing behavior of the whole. In this study, we prepared samples of $\mathrm{Al}$ particles encapsulated in $\mathrm{Al}_{2} \mathrm{O}_{3}$ shells to eliminate possible effects of oxidation and coalescence at high temperatures. By using differential scanning calorimeter (DSC), we quantitatively measured the $\Delta T^{+}-\Delta T^{-}$relationship of encapsulated Al particles and found a remarkable dependence of $\Delta T^{-}$on $\Delta T^{+}$that extends to ultrahigh $\Delta T^{+}$levels.

\section{Materials and Methods}

$\mathrm{Al}$ small particles were prepared by means of active $\mathrm{H}_{2}$ plasma evaporation and condensation, using bulk $\mathrm{Al}$ (with a purity of $99.8 \%$ ) as the starting material. The particles were in situ passivated at room temperature before exposure to air. The passivated $\mathrm{Al}$ particles were further oxidized in air to produce a thick surface oxide shell. Samples with different oxidation extents were produced by changing the temperature/duration of oxidation.

The morphology and size of Al particles was investigated by a transmission electron microscope (TEM, Philips, Amsterdam, The Netherlands) and a high-resolution transmission electron microscope (HRTEM, JEOL, Tokyo, Japan), which was conducted on a Philips EM 420 microscope (Philips) with an accelerating voltage of $100 \mathrm{kV}$ and a JEM 2010 high-resolution microscope (JEOL) with an accelerating voltage of $200 \mathrm{kV}$, respectively. Samples for TEM and HRTEM observations were prepared by dispersing the particles in ethanol by sonication and then, dropping on a carbon-coated copper grid. Formation of an oxide shell on the Al particle surface was confirmed by TEM and HRTEM observations. The surface oxide shell was found to be able to retain the shape of Al particles effectively upon heating and cooling so that the particle can melt and freeze independently.

Thermal analysis was performed on a Netzsch high-temperature differential scanning calorimeter (DSC 404C, Netzsch, Selb, Germany). The sample in $\mathrm{Al}_{2} \mathrm{O}_{3}$ crucible was measured in a dynamic Ar atmosphere with a gas flow rate of $50 \mathrm{~mL} / \mathrm{min}$ and a heating/cooling rate of $20{ }^{\circ} \mathrm{C} / \mathrm{min}$. The temperature and enthalpy were calibrated by the melting endotherms of pure In, $\mathrm{Al}$ and $\mathrm{Ag}$.

\section{Results and Discussion}

As shown in Figure 1a, the original Al particles are nearly spherical in shape with sizes mostly ranged from $\sim 30$ to $\sim 500 \mathrm{~nm}$. Al particles were encapsulated in $\mathrm{Al}_{2} \mathrm{O}_{3}$ shells after thermal oxidation at $500^{\circ} \mathrm{C}$ for $90 \mathrm{~min}$ in air (Figure $1 \mathrm{~b}, \mathrm{c}$ ). X-ray diffraction (XRD) analysis also confirmed the formation of oxide shells (Figure 1d). The $\mathrm{Al}_{2} \mathrm{O}_{3}$ shells are able to prevent the coalescence of Al nanoparticles upon heating and retain the particles shape even at temperatures well above $T_{0}[17,18]$, allowing for the independent melting and solidification of encapsulated $\mathrm{Al}$ particles.

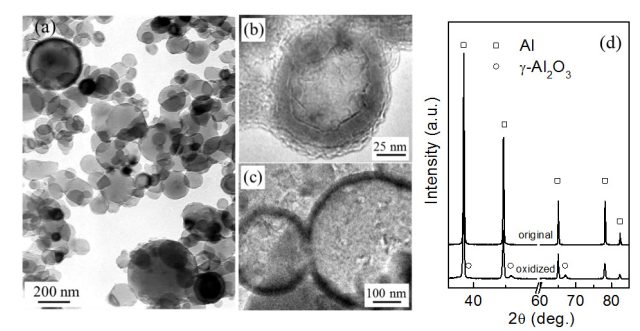

Figure 1. (a) A bright-field transmission electron microscope (TEM) image of the as-evaporated (original) Al particles; (b,c) high-resolution transmission electron microscope (HRTEM) images of small and large $\mathrm{Al}$ particles oxidized at $500{ }^{\circ} \mathrm{C}$ for $90 \mathrm{~min}$, showing existence of the surface oxide shell; (d) XRD profiles of the original and oxidized (at $500{ }^{\circ} \mathrm{C}$ for $90 \mathrm{~min}$ ) $\mathrm{Al}$ particles. 
The melting and solidification behaviors of encapsulated Al particles were measured by DSC. As shown in Figure 2a, melting endotherms of encapsulated Al particles are quite similar after several heating/cooling cycles, showing a reduced melting temperature (onset temperature of the melting peak: $\sim 650{ }^{\circ} \mathrm{C}$ ) due to the size-dependent melting point depression [19]. It is noted that previous studies [20-23] indicated the important effects of stress relaxation and damage of the oxide shell on the melting of Al nanoparticles coated by oxide shells, while in the present study the good repeatability of melting endotherms suggests the good thermal stability of encapsulated Al particles after several DSC thermal cycles, which may be attributed to the thicker oxide shells that were formed by thermal oxidation in the present study. Figure $2 \mathrm{~b}$ demonstrates DSC curves of the Al particles cooled from different liquid temperatures/overheating levels. All DSC curves consist of two main exothermic peaks, one with small supercooling (P1) and another with larger supercooling (P2). Most importantly, the solidification behavior shows an evident dependence on the liquid temperature. For a quantitative illustration, we take $\Delta T^{-}$as the difference between the onset temperature of $\mathrm{P} 1$, and $T_{0}$ of $\mathrm{Al}$ and $\Delta T^{+}$, as that between the liquid temperature and $T_{0}$. As shown in Figure 2c, an evident dependence of $\Delta T^{-}$on $\Delta T^{+}$is identified: $\Delta T^{-}$increases with the increasing of $\Delta T^{+}$, most evidently in the $\Delta T^{+}$ range of $140-340^{\circ} \mathrm{C}$. In Figure $2 \mathrm{c}$, the relative area ratio of the two peaks $(A 1 / A 2)$ also shows a strong dependence on $\Delta T^{+}$, indicating that when cooled from higher liquid temperatures, more Al particles solidify at larger supercoolings. In our experiments, the holding time at which the liquid was kept at $\Delta T^{+}$(up to $1 \mathrm{~h}$ ) was found to have little effect on the $\Delta T^{+}-\Delta T^{-}$relationship, and the supercooling behavior was only related to the highest temperature to which the liquid was heated, regardless of the intermediate temperatures at which it was held before solidification, in agreement with predictions by the cavity theory [14]. Compared to previous experiments using fast scanning calorimetry with a ultrahigh cooling rate up to the order of $10^{5} \mathrm{C} / \mathrm{min}[2,14,24,25]$, the cooling rate in the present study is very small $\left(20^{\circ} \mathrm{C} / \mathrm{min}\right)$, which can exclude the cooling rate effect on the solidification of $\mathrm{Al}$ particles cooled from different liquid temperatures and rationalize the independence of the holding time at $\Delta T^{+}$. To confirm the reproducibility of the results and clarify possible effects of the morphologies changes on the oxidized $\mathrm{Al}$ particles induced by the high-temperature annealing/heating on the freezing behavior, we carried out several heating-cooling cycles for different heating temperatures of the liquid and obtained DSC curves immediately after the $1200^{\circ} \mathrm{C}$ heating-cooling cycle. As shown in Figure $3, \Delta T^{-}$ still shows an evident dependence on $\Delta T^{+}$regardless of the previous $1200^{\circ} \mathrm{C}$ heating-cooling cycle, indicating that the freezing behavior is only dependent on the maximum liquid heating temperature before solidification. We also carried out DSC measurements on samples with different oxidation degrees prepared by changing oxidation temperature/duration, all showing a similar $\Delta T^{+}-\Delta T^{-}$ relationship, i.e., $\Delta T^{-}$increases with increasing $\Delta T^{+}$(Figure 4a-c). To our knowledge, such $\Delta T^{+}-\Delta T^{-}$ relationship has not been reported in $\mathrm{Al}$ before. Moreover, the $\Delta T^{+}$level (up to $340^{\circ} \mathrm{C}$ ) to which the dependence of $\Delta T^{-}$on $\Delta T^{+}$extends in the present study is significantly larger than that observed in other metals and alloys (typically several to tens of degrees) [14].

For comparison, bulk Al samples with different impurity levels were also tested, as shown in Figure $4 \mathrm{~d}-\mathrm{f}$. For bulk $\mathrm{Al}$ sample with a purity of $99.999 \%$, the solidification behavior varies randomly for each heating-cooling cycle, which is due to the accidental nature of catalysts for nucleation of solidification. For bulk Al sample with a purity of $99.8 \%$, the DSC cooling curves are similar for different $\Delta T^{+}$s, with a smaller supercooling than bulk Al sample with a higher purity level (99.999\%), which simply can be attributed to the higher content of catalysts for nucleation. The supercooling behavior of the consolidated sample, made by cold-pressing the oxidized Al particles, remains almost unchanged for different $\Delta T^{+} \mathrm{s}$ although two exothermic peaks are also observed, i.e., no dependence of $\Delta T^{-}$on $\Delta T^{+}$as that in the powder sample is observed. This is possible because, as mentioned above, in bulk continuous systems, crystallization centers in one region may affect the solidification behavior of the whole. It is also shown in Figure 4 that the solidification temperatures of P1 of the powder sample, the consolidated sample, and bulk Al sample with a purity of $99.8 \%$ are similar but different from that of the bulk Al sample with a purity of $99.999 \%$, indicating the important effect of impurities. 
For a particle/droplet, different nucleation mechanisms, namely bulk and surface nucleation, can have significant effects on the solidification behavior [24,25]. To identify the two solidification processes of $\mathrm{Al}$ particles, the sample was heated to different temperatures followed by cooling down so that only a part of $\mathrm{Al}$ particles in the sample were melted and solidified. As shown in Figure 5, Al particles melted at lower temperatures tend to solidify at larger supercoolings (P2), and those with higher melting temperatures at smaller supercoolings (P1). Since smaller particles have lower melting points than larger ones due to the size effect [19], it is believed that P1 corresponds to the solidification of larger Al particles while P2 corresponds to smaller ones. Previous studies [26,27] showed that the multi-stage solidification behaviors in various embedded particle/matrix systems can be related to the different catalyzing effects of impurities and matrix/coating. Hereby, we can further conclude that P1 corresponds to the solidification of larger particles (with more impurities) related to the catalyzing effect of impurities while P2 corresponds to smaller particles (with less impurities) catalyzed by the coating. It is noted that previous phase field simulations [28] indicated that $\mathrm{Al}$ melt can completely wet alumina with a contact angle of zero. However, interfacial energy between $\mathrm{Al}$ and $\mathrm{Al}_{2} \mathrm{O}_{3}$ is also dependent on factors such as crystallography, temperature, impurity, etc. Here, it is believed that upon solidification, heterogeneous nucleation on the $\mathrm{Al} / \mathrm{Al}_{2} \mathrm{O}_{3}$ interface would be more likely than homogenous nucleation, as long as upon nucleation the $\mathrm{Al} / \mathrm{Al}_{2} \mathrm{O}_{3}$ interface is formed so that the contact angle of solid $\mathrm{Al}$ on $\mathrm{Al}_{2} \mathrm{O}_{3}$ is between $0^{\circ}$ and $180^{\circ}$, by e.g., forming a favored local crystallography. The relative change in peak areas shown in Figure $2 \mathrm{c}$ where the increasing $\Delta T^{+}$is due to the modification of the two nucleation sites upon elevated temperature exposure: bulk heterogeneous nucleation (P1) and surface/interface heterogeneous nucleation (P2). The above analysis indicates that the dependence of $\Delta T^{-}$on $\Delta T^{+}$of encapsulated $\mathrm{Al}$ particles observed in the present experiment is related to effect of impurity (alloying) atoms despite the minute amount. Hereby, a critical problem is how the liquid overheating can lead to a transfer between the two nucleation mechanisms, i.e., how bulk heterogeneous nucleation is suppressed by liquid overheating.
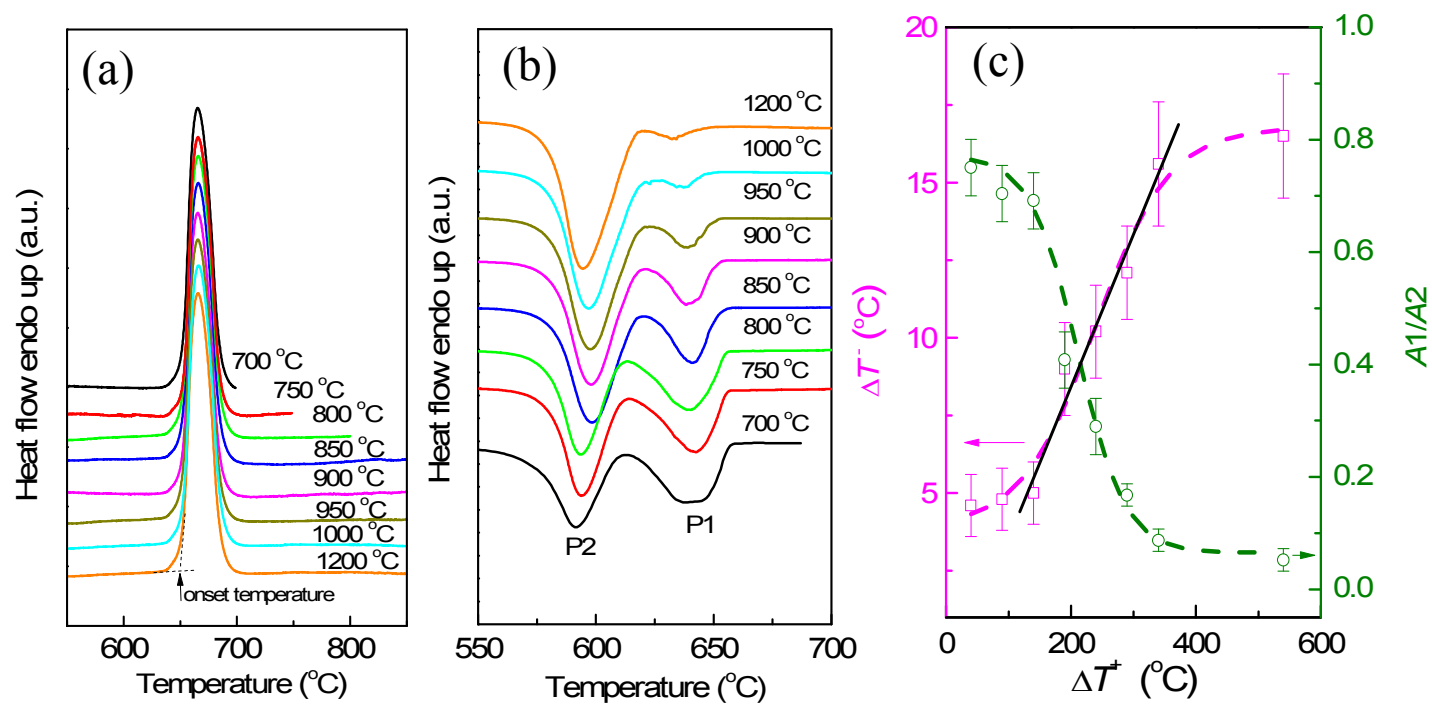

Figure 2. (a) Differential scanning calorimeter (DSC) melting curves of the encapsulated Al particles (oxidized at $500{ }^{\circ} \mathrm{C}$ for $90 \mathrm{~min}$ ) heated to different temperatures as indicated, showing the good repeatability of melting endotherms after several thermal cycles. The definition of the onset temperature of DSC peak is indicated in (a); (b) DSC curves of the encapsulated $\mathrm{Al}$ particles (oxidized at $500{ }^{\circ} \mathrm{C}$ for $90 \mathrm{~min}$ ) cooled from different temperatures as indicated, showing variations of the two freezing exotherms P1 and P2 with liquid temperature; (c) Variations of $\Delta T^{-}$of P1 and relative area ratio of P1 to $\mathrm{P} 2(A 1 / A 2)$ as functions of $\Delta T^{+}$. In (c), the dashed lines are guides for eyes, and the solid line is a linear fitting of the data in the $\Delta T^{+}$range of $140-340{ }^{\circ} \mathrm{C}$. 

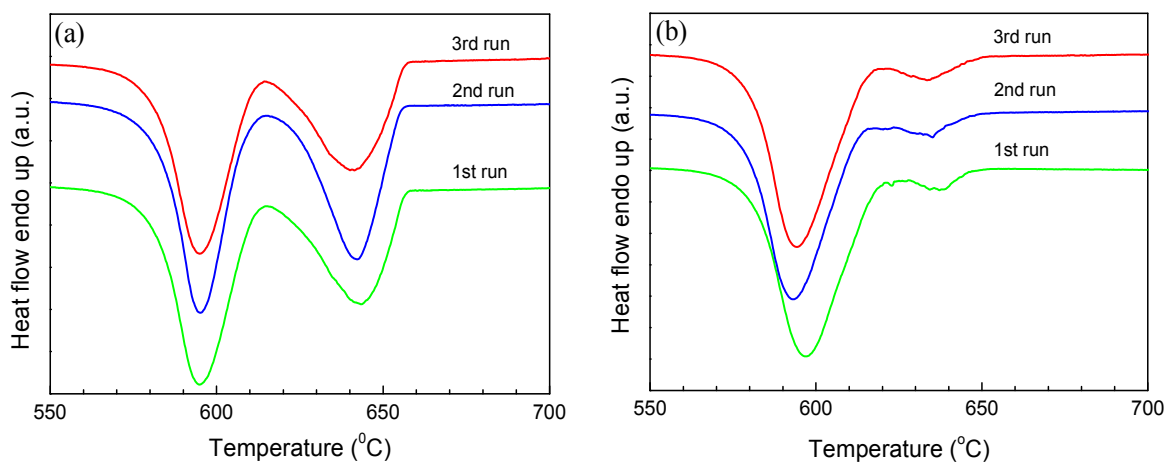

Figure 3. DSC cooling curves of the encapsulated Al particles (oxidized at $500{ }^{\circ} \mathrm{C}$ for $90 \mathrm{~min}$ ) for different liquid overheating temperatures (a) $800{ }^{\circ} \mathrm{C}$ and (b) $1000{ }^{\circ} \mathrm{C}$. Each run was performed immediately after a previous $1200^{\circ} \mathrm{C}$ heating-cooling cycle.
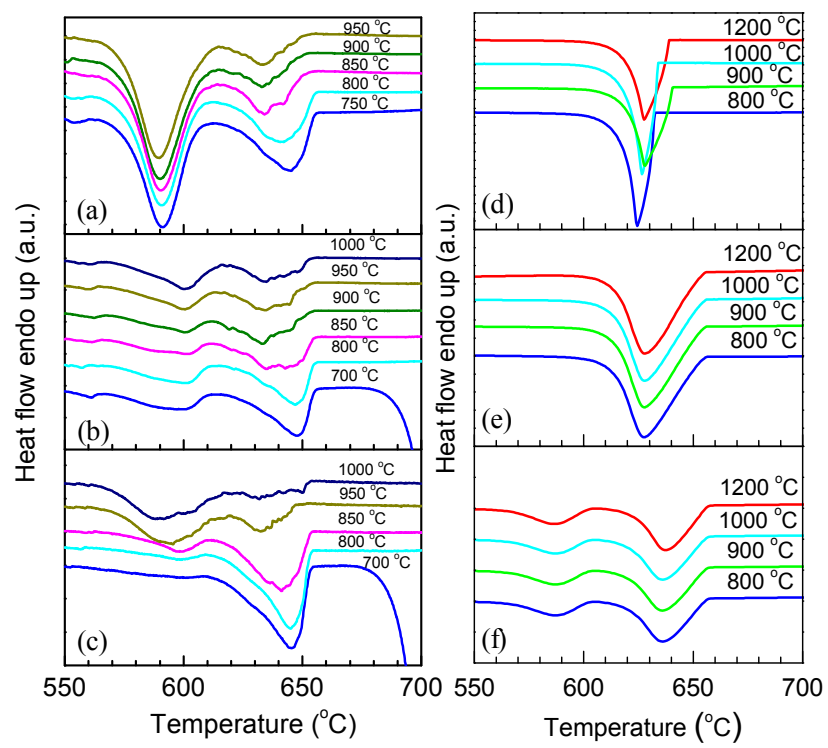

Figure 4. DSC curves corresponding to the cooling from different temperatures as indicated for different samples. (a) Al particles oxidized at $700{ }^{\circ} \mathrm{C}$ for $90 \mathrm{~min}$; (b) Al particles oxidized at $800{ }^{\circ} \mathrm{C}$ for $180 \mathrm{~min}$; (c) Al particles oxidized at $900{ }^{\circ} \mathrm{C}$ for $180 \mathrm{~min}$; (d) $99.999 \%$ bulk Al; (e) $99.8 \%$ bulk Al; (f) Consolidated samples of oxidized $\mathrm{Al}$ particles (at $500{ }^{\circ} \mathrm{C}$ for $90 \mathrm{~min}$ ) made by cold pressing.

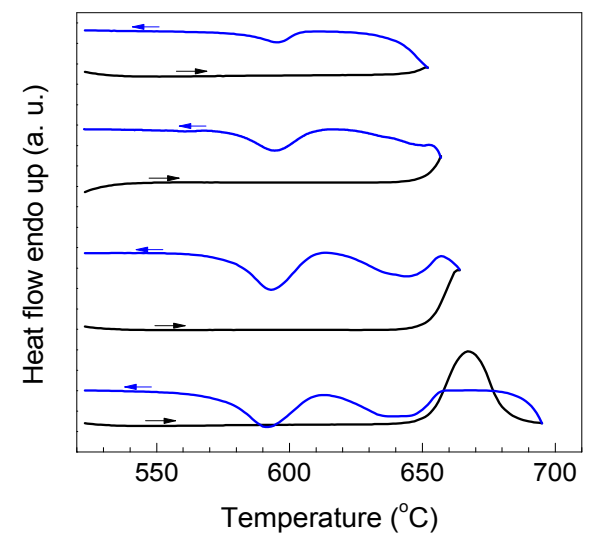

Figure 5. DSC partial melting-cooling curves for the encapsulated $\mathrm{Al}$ particles (oxidized at $500{ }^{\circ} \mathrm{C}$ for $90 \mathrm{~min}$ ). Melting of the encapsulated $\mathrm{Al}$ particles was interrupted at different temperatures (as indicated) for $60 \mathrm{~s}$ before the cooling step. 
The dependence of $\Delta T^{-}$on $\Delta T^{+}$obtained in our study indicates the existence of temperature-dependent crystals in liquid $\mathrm{Al}$ up to a very high $\Delta T^{+}\left(\sim 340^{\circ} \mathrm{C}\right)$, unlike the transient short range orders as in the cases of semimetals and semiconductors [11,12]. Previous studies indicated that the crystals confined by a coating/matrix can be superheated metastably providing epitaxial

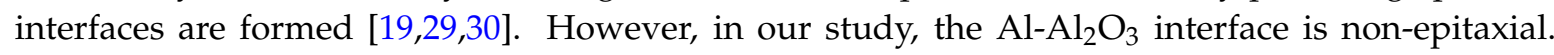
Although a small pressure-induced superheating up to $\sim 15^{\circ} \mathrm{C}$ was observed [31], it cannot obviously account for the very large superheating $\left(\sim 340^{\circ} \mathrm{C}\right)$ that is close to the inverse Kauzmann point (highest superheating limit) [32] in the present study. As mentioned above, the cavity theory [14] provided a possible explanation for the dependence of $\Delta T^{-}$on $\Delta T^{+}$. According to the cavity theory [14], a crystal contained in a cavity with a radius of $r$ can remain unmelted at a certain liquid overheating level $\left(\Delta T^{+}\right)$, given by:

$$
\Delta T^{+}=\frac{2 T_{0} \sigma_{\mathrm{sl}} \cos \theta}{\Delta H_{\mathrm{m}} r}
$$

where $\sigma_{\mathrm{sl}}$ is the solid-liquid interfacial energy of the host metal, $\theta$ is the contact angle between the cavity and the host liquid, and $\Delta H_{\mathrm{m}}$ is the melting enthalpy of the host metal. The cavity theory predicted a linear relationship between $\Delta T^{+}$and $\Delta T^{-}$[14]:

$$
\Delta T^{-} / \Delta T^{+}=\tan \theta
$$

In the present experiment, the $\Delta T^{+}-\Delta T^{-}$relationship in the $\Delta T^{+}$range of 140 to $340{ }^{\circ} \mathrm{C}$ is approximately linear, as shown in Figure 2. By linear fitting of the experimental data according to Equation (2), we get $\theta=2.6^{\circ}$. Meanwhile, for $\Delta T_{\max }^{+}=340^{\circ} \mathrm{C}$ and $\Delta T_{\min }^{+}=140^{\circ} \mathrm{C}$ with available data of $\Delta H_{\mathrm{m}}$ and $\sigma_{\mathrm{sl}}$ for $\mathrm{Al}$ [33], we get $r_{\min }=0.6 \mathrm{~nm}$ and $r_{\max }=1.5 \mathrm{~nm}$ from Equation (1), corresponding to the radius of the smallest and largest cavities, respectively. However, the existence of cavities with such extremely small sizes and contact angles is hardly reasonable, indicating the insufficiency of the cavity theory for interpreting the dependence of $\Delta T^{-}$on $\Delta T^{+}$extending to ultrahigh $\Delta T^{+}$in the present experiment. In a Ni-base superalloy, existence of $\mathrm{Ni}_{3}(\mathrm{Al}, \mathrm{Ti}, \mathrm{Nb})$-like clusters and residual $\mathrm{MC}$ $(\mathrm{M}=\mathrm{Nb}, \mathrm{Ti})$ carbide in the alloy melt superheated to $1500^{\circ} \mathrm{C}\left(170^{\circ} \mathrm{C}\right.$ above the liquidus temperature $)$ was detected by high temperature $\mathrm{X}$-ray diffraction, resulting in a liquid thermal history effect on solidification [6]. Hereby, a possible consideration is that the persisted crystals are not likely pure $\mathrm{Al}$ but alloyed clusters containing $\mathrm{Al}$ and other (impurity) atoms, as indicated by the impurity-related evidence of the dependence of $\Delta T^{-}$on $\Delta T^{+}$in the present study. However, for a better interpretation of the present results, direct experimental evidence for the size, surface energy, and melting point of these clusters is needed.

\section{Conclusions}

In summary, through quantitative experimental measurements, we found a remarkable dependence of $\Delta T^{-}$on $\Delta T^{+}$extending to ultrahigh $\Delta T^{+}$levels in $\mathrm{Al}$ small particles encapsulated in $\mathrm{Al}_{2} \mathrm{O}_{3}$ shells. While the analysis pointed to the existence of temperature-dependent crystallization centers in liquid $\mathrm{Al}$ at very high liquid temperatures, the cavity theory was found to be insufficient to interpret the present results. The present study highlighted quantitatively the significant effect of liquid overheating levels on the supercooling behavior of $\mathrm{Al}$ and $\mathrm{Al}$ alloys, and raised new considerations for the dependence of liquid supercooling on liquid overheating at very high liquid overheating levels.

Acknowledgments: Financial supports from the National Natural Science Foundation of China (Grant 51371128) and Wuhan University (Grant 410100018) are gratefully acknowledged.

Author Contributions: Qingsong Mei conducted the experiments. Qingsong Mei and Juying Li contributed to the analyses and discussion of the results and prepared the manuscript.

Conflicts of Interest: The authors declare no conflict of interest. 


\section{References}

1. Fine, M.E. Introduction to Phase Transformations in Condensed Systems; Macmillan: New York, NY, USA, 1964.

2. Yang, B.; Perepezko, J.H.; Schmelzer, J.W.P.; Gao, Y.L.; Schick, C. Dependence of crystal nucleation on prior liquid overheating by differential fast scanning calorimeter. J. Chem. Phys. 2014, 140, 104513. [CrossRef] [PubMed]

3. Webster, W.L. Phenomena occurring in the melting of metals. Proc. R. Soc. Lond. Ser. A 1933, 140, $653-660$. [CrossRef]

4. Richard, W.T. The persistence and development of crystal nuclei above the melting temperature. J. Am. Chem. Soc. 1932, 54, 479-495. [CrossRef]

5. Luzny, W. Kinetics of heterogeneous nucleation and the "memory effect" in liquid gallium. J. Phys. Condens. Matter 1990, 2, 10183-10190. [CrossRef]

6. Yin, F.S.; Sun, X.F.; Guan, H.R.; Hu, Z.Q. Effect of thermal history on the liquid structure of a cast nickel-base superalloy M963. J. Alloy. Compd. 2004, 364, 225-228. [CrossRef]

7. Koh, H.J.; Rudolph, P.; Schafer, N.; Umetsu, K.; Fukuda, T. The effect of various thermal treatments on supercooling of PbTe melts. Mater. Sci. Eng. B 1995, 34, 199-203. [CrossRef]

8. Muhlbug, M.; Rudolph, P.; Laasch, M. The correlation between superheating and supercooling in CdTe melts during unseeded bridgman growth. J. Cryst. Growth 1993, 128, 571-575. [CrossRef]

9. Rudolph, P.; Koh, H.J.; Schafer, N.; Fukuda, T. The crystal perfection depends on the superheating of the mother phase too-Experimental facts and speculations on the "melt structure" of semiconductor compounds. J. Cryst. Growth 1996, 166, 578-582. [CrossRef]

10. Tong, H.Y.; Shi, F.G. Dependence of supercooling of a liquid on its overheating. J. Chem. Phys. 1997, 107, 7964-7966. [CrossRef]

11. Tong, H.Y.; Shi, F.G. Abrupt discontinuous relationships between supercooling and melt overheating. Appl. Phys. Lett. 1997, 70, 841-843. [CrossRef]

12. Zhou, Z.; Wang, W.; Sun, L. Undercooling and metastable phase formation in a Bi95Sb5 melt. Appl. Phys. A 2000, 71, 261-265. [CrossRef]

13. Zhao, B.; Li, L.; Lu, F.; Zhai, Q.; Yang, B.; Schick, C.; Gao, Y. Phase transitions and nucleation mechanisms in metals studied by nanocalorimetry: A review. Thermochim. Acta 2015, 603, 2-23. [CrossRef]

14. Turnbull, D. Kinetics of heterogeneous nucleation. J. Chem. Phys. 1950, 18, 198-203. [CrossRef]

15. Li, P.; Nikitin, V.I.; Kandalova, E.G.; Nikitin, K.V. Effect of melt overheating, cooling and solidification rates on Al-16wt.\%Si alloys. Mater. Sci. Eng. A 2002, 332,371-374. [CrossRef]

16. Xu, C.L.; Jiang, Q.C. Morphologies of primary silicon in hypereutectic Al-Si alloys with melt overheating temperature and cooling rate. Mater. Sci. Eng. A 2006, 437, 451-455. [CrossRef]

17. Révész, Á.; Lendvai, J.; Ungár, T. Melting point depression and microstructure in ball-milled nanocrystalline aluminium powders. J. Metastab. Nanocryst. Mater. 2000, 8, 326-331. [CrossRef]

18. Echert, J.; Holzer, J.C.; Ahn, C.C.; Fu, Z.; Johnson, W.L. Melting behavior of nanocrystalline aluminum powders. Nanostruct. Mater. 1993, 2, 407-413. [CrossRef]

19. Mei, Q.S.; Lu, K. Melting and superheating of crystalline solids: From bulk to nanocrystals. Prog. Mater. Sci. 2007, 52, 1175-1262. [CrossRef]

20. Sun, J.; Simon, S.L. The melting behavior of aluminum nanoparticles. Thermochim. Acta 2007, 463, 32-40. [CrossRef]

21. Levitas, V.I.; Pantoya, M.L.; Chauhan, G.; Rivero, I. Effect of the alumina shell on the melting temperature depression for aluminum nanoparticles. J. Phys. Chem. C 2009, 113, 14088-14096. [CrossRef]

22. Ruffino, B.; Coulet, M.V.; Bouchet, R.; Isnard, O.; Denoyel, R. Structural changes and thermal properties of aluminium micro- and nano-powders. Acta Mater. 2010, 58, 4224-4232. [CrossRef]

23. Firmansyah, D.A.; Sullivan, K.; Lee, K.S.; Kim, Y.H.; Zahaf, R.; Zachariah, M.R.; Lee, D. Microstructural behavior of the alumina shell and aluminum core before and after melting of aluminum nanoparticles. J. Phys. Chem. C 2012, 116, 404-411. [CrossRef]

24. Yang, B.; Abyzov, A.S.; Zhuravlev, E.; Gao, Y.L.; Schmelzer, J.W.P.; Schick, C. Size and rate dependence of crystal nucleation in single tin drops by fast scanning calorimetry. J. Chem. Phys. 2013, 138, 054501. [CrossRef] [PubMed] 
25. Yang, B.; Gao, Y.L.; Zou, C.D.; Zhai, Q.J.; Abyzov, A.S.; Schmelzer, J.W.P.; SchickSize, C. Cooling rate dependence of undercooling of pure Sn single drop by fast scanning calorimetry. Appl. Phys. A 2011, 104, 189-196. [CrossRef]

26. Moore, K.I.; Zhang, D.L.; Cantor, B. Solidification of Pb particles embedded in Al. Acta Metall. Mater. 1990, 38, 1327-1342. [CrossRef]

27. Goswami, R.; Chattopadhyay, K.; Kim, W.T.; Cantor, B. Heterogeneous nucleation of Pb particles embedded in a Zn matrix. Metall. Trans. A 1992, 23, 3207-3218. [CrossRef]

28. Levitas, V.I.; Samani, K. Melting and solidification of nanoparticles: Scale effects, thermally activated surface nucleation, and bistable states. Phys. Rev. B 2014, 89, 075427. [CrossRef]

29. Cahn, R. Melting and the surface. Nature 1986, 323, 668-669. [CrossRef]

30. Sheng, H.W.; Ren, G.; Peng, L.M.; Hu, Z.Q.; Lu, K. Superheating and melting-point depression of Pb nanoparticles embedded in Al matrices. Philos. Mag. Lett. 1996, 73, 179-186. [CrossRef]

31. Mei, Q.S.; Wang, S.C.; Cong, H.T.; Jin, Z.H.; Lu, K. Pressure-induced superheating of Al nanoparticles encapsulated in $\mathrm{Al}_{2} \mathrm{O}_{3}$ shells without epitaxial interface. Acta Mater. 2005, 53, 1059-1066. [CrossRef]

32. Fecht, H.J.; Johnson, W.L. Entropy and enthalpy catastrophe as a stability limit for crystalline material. Nature 1988, 334, 50-51. [CrossRef]

33. Pluis, B.; Frenkel, D.; van der Veen, J.F. Surface-induced melting and freezing II. A semi-empirical Landau-type model. Surf. Sci. 1990, 239, 282-300.

(C) 2015 by the authors; licensee MDPI, Basel, Switzerland. This article is an open access article distributed under the terms and conditions of the Creative Commons by Attribution (CC-BY) license (http://creativecommons.org/licenses/by/4.0/). 